\title{
A complication of internal fixation rods in sport
}

\author{
Ofer Levy MD, Amos Schindler MD, Aaron Chechik MD and Michael Heim MD \\ Department of Orthopaedic Surgery B, Chaim Sheba Medical Center, Israel
}

Methods of internal fixation of broken bones are numerous. Rigid fixation allows early mobilization and also a better anatomical reduction of the fractured bone.

Once solid bony union has occurred patients are asymptomatic and return to participation in sports.

The surgeon is often faced with opposition when he suggests that the sportsman should once again subject himself to surgery and have the painless, asymptomatic internal fixation device removed. This short case report highlights the necessity for the removal of the foreign material.

\section{Case report}

A 30-year-old man presented at the casualty department complaining of a painful right knee after sustaining a rotational injury during a jump. The patient reported a sharp tearing sensation. On examination a haemarthrosis was noted with a gap in the continuity of the patellar tendon and the extensor mechanism of the knee absent. The medical history revealed that the patient had had a Herzog-Küntscher intramedullary nail installed in his right tibia 12 years earlier following a fracture. Since operation the patient had been asymptomatic and had refused to allow removal of the nail. The radiograph obtained in the casualty department shows slight proximal migration of the intramedullary nail with protrusion and a raised patella (Figure 1)

At operation a complete degenerative tear of the patellar tendon was found, with chronic fibrous changes of the tendon and adhesions inside the knee. The intramedullary nail was removed and the tendon sutured, including reinforcement with partial thickness middle third of the quadriceps tendon ${ }^{1}$. The patient's recovery was uneventful.

\section{Discussion}

The continuing friction of the patellar tendon over the proximal protruding edge of the nail had resulted in degenerative changes and partial tears of the tendon

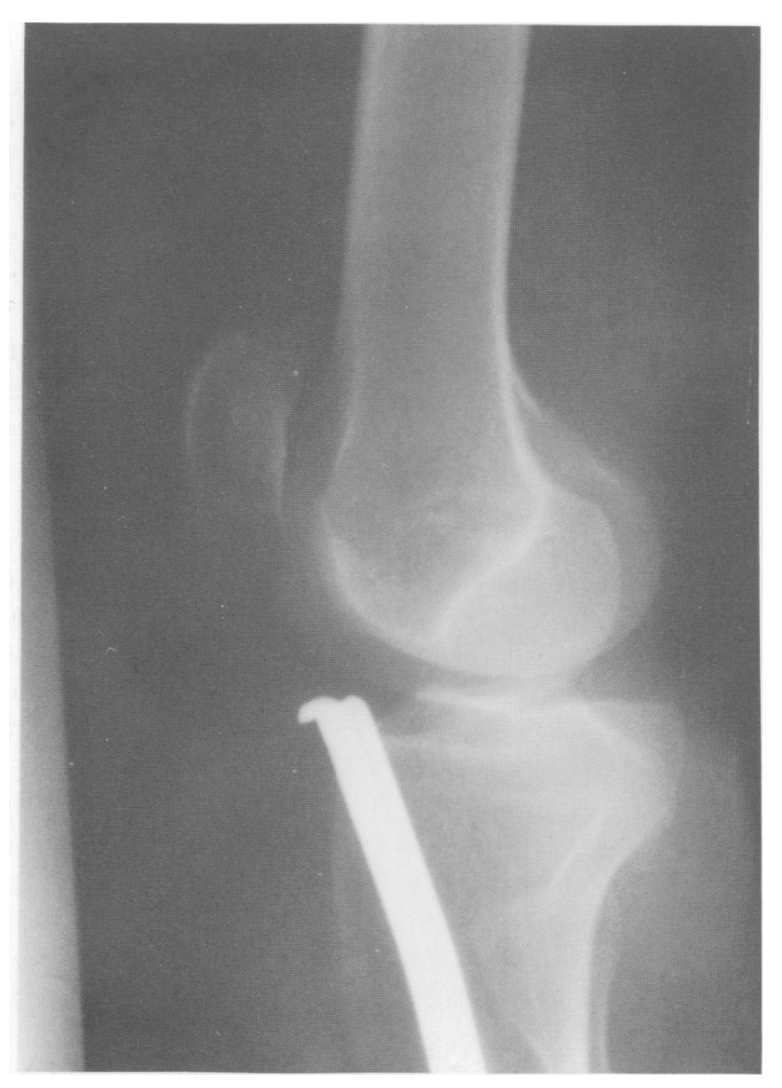

Figure 1. Radiograph of right knee of 30-year-old man showing slight proximal migration of the intramedullary nail with protrusion and a raised patella

fibres. The jump created the force which was needed to complete the tear of the entire tendon.

The timely removal of the intramedullary nail would have avoided the degeneration of the patellar tendon and its ultimate tear.

\section{Reference}

1 Crenshaw AH. Campbell's Operative Orthopaedics, 7th ed St Louis, USA: CV Mosby, 1987: 2233-7. 